\title{
Moving towards a population health approach to the primary prevention of common mental disorders
}

Felice N Jacka ${ }^{1,2^{*}}$, Arnstein Mykletun ${ }^{3,4}$ and Michael Berk ${ }^{1,2,5,6}$

\begin{abstract}
There is a need for the development of effective universal preventive approaches to the common mental disorders, depression and anxiety, at a population level. Poor diet, physical inactivity and smoking have long been recognized as key contributors to the high prevalence noncommunicable diseases. However, there are now an increasing number of studies suggesting that the same modifiable lifestyle behaviors are also risk factors for common mental disorders. In this paper we point to the emerging data regarding lifestyle risk factors for common mental disorders, with a particular focus on and critique of the newest evidence regarding diet quality. On the basis of this most recent evidence, we consequently argue for the inclusion of depression and anxiety in the ranks of the high prevalence noncommunicable diseases influenced by habitual lifestyle practices. We believe that it is both feasible and timely to begin to develop effective, sustainable, population-level prevention initiatives for the common mental illnesses that build on the established and developing approaches to the noncommunicable somatic diseases.
\end{abstract}

Keywords: Anxiety, etiology, common mental disorders, diet, depression, lifestyle, physical activity, prevention, risk, smoking

\section{Background}

The common mental disorders, depression and anxiety, are major public health problems across the globe. Unipolar depression now accounts for the largest burden of disability in the developed world, reducing functional capacity [1] and increasing the risk for early mortality across causes of death [2]. In many medical disorders, from infections to cancer and cardiovascular disorders, the greatest contribution to health has been through prevention rather than treatment. However, prevention at a public health level in psychiatric disorders has received less attention than individualized treatment efforts. Thus, there is a need for the development of effective universal preventive approaches to the common mental disorders at a population level [3].

One of the great complexities of the preventative paradigm in psychiatry is the sheer plethora of interacting

\footnotetext{
* Correspondence: felice@barwonhealth.org.au

'Deakin University, School of Medicine and Barwon Health, PO Box 281, Geelong, 3220, Australia

Full list of author information is available at the end of the article
}

factors of variable plasticity and reversibility. While other potentially modifiable factors, including social inequality, social networks, child abuse, and drug and alcohol abuse, play a role in depression risk, preventative efforts need to focus on areas of greatest plasticity and reach, whilst acknowledging the role of the other factors. One such plastic factor is lifestyle, a term which encompasses diet, physical activity and smoking.

Poor diet, physical inactivity and smoking have long been recognized as key contributors to the high prevalence noncommunicable diseases, such as heart disease, type 2 diabetes and cancer. However, there are now an increasing number of studies suggesting that the same modifiable lifestyle behaviors are also risk factors for common mental disorders. Growing evidence indicates a role for physical inactivity as a risk factor for common mental disorders (for example [4-6]), while exercise has been shown to be effective in treatment studies [7]. There is some evidence for smoking also independently increasing the risk for common mental disorders [8-10]. Diet quality is the most recent area of attention in the lifestyle-mental health 
research field. Here we make the important distinction between habitual dietary intakes and the limited and inconsistent literature on nutritional supplementation as a treatment for depression, wherein, apart from omega 3 fatty acids in severe depression [11] and folate as an adjunctive treatment [12], there is little quality evidence for effectiveness [13]. Neither will we address the literature on the dietary intake of individual nutrients and depression (for review see [14]) as these are also equivocal and likely confounded by overall dietary quality.

In this paper we will present a brief overview of the recent observational data regarding diet quality as a risk factor for common mental disorders. This new evidence base adds to what is already known about the importance of physical activity to depression and the developing evidence regarding smoking as an independent risk factor for depression; as such it can be considered 'the final piece in the lifestyle puzzle'. On the basis of this newest evidence, we will thus argue for the inclusion of depression and anxiety in the ranks of the high prevalence noncommunicable disorders influenced by habitual lifestyle practices. We will also argue for the imperative to develop universal primary prevention strategies for common mental disorders, applying the lessons of successes and failures of population health approaches that have been used for other noncommunicable disorders.

\section{Discussion}

What is the evidence for an association between diet quality and the common mental disorders?

In 2010, in a population-based study of over 1,000 adult women, Jacka et al. [15] reported that women who had a diet characterized by a higher intake of unhealthy westerntype foods were more likely to have either major depression or dysthymia, while those whose diets were higher in recognized healthy foods, such as vegetables, lean meats, fish and wholegrains, were less likely to have clinical depressive or anxiety disorders. Similar associations were observed between diet quality and bipolar disorder in the same cohort [16]. Subsequent investigations in a study of more than 5,000 population-based Norwegians demonstrated that adults with better quality diets were less likely to be depressed, while a higher intake of processed and unhealthy foods was associated with increased anxiety [17]. These studies are complemented by prospective studies from other groups: data from the SUN Cohort study in Spain, based on more than 10,000 middle-aged university graduates, demonstrated a prospective inverse association over approximately four and a half years between the level of adherence to a Mediterranean dietary pattern and the risk for incident depression, and a positive association between the consumption of fast foods and commercial baked goods and depression risk $[18,19]$. In the Whitehall II cohort study of nearly 3,500 public servants, the authors observed an increased risk for self-reported depression for those on a diet higher in western-style foods, and reduced risk for those on a diet higher in whole foods over approximately five years of follow-up [20]. In 529 women participating in the RHEA mother and baby cohort study, women with better quality diets during pregnancy were at reduced risk for postpartum depression [21]. Numerous recent cross-sectional studies from research groups in Japan [22,23], China [24], the US [25-28] and elsewhere have supported these findings in adults. It is worth noting that these studies regarding dietary intake are also supported by studies showing that serum folate concentrations, which are markers of dietary quality, predict depression risk over time [29].

Given that adolescence is the age of risk for the onset of these disorders, it is noteworthy that similar data exist in population-based child and adolescent studies: in a 2009 study of more than 1,300 adolescents, Oddy et al. [30] reported that those eating a diet characterized by higher intakes of takeaway foods, red meat and confectionary had increased internalizing and externalizing behaviors, whilst the intake of fruits and vegetables showed the opposite association. In a Chinese study of more than 5,000 young adolescents, healthy dietary habits were associated with reduced psychological symptoms, whilst unhealthy dietary habits had a positive relationship with such symptoms [31]. Similarly, a study of 7,000 young population-based adolescents reported inverse relationships between measures of diet quality and the likelihood of adolescent depression, with higher scores on an unhealthy dietary measure associated with increased symptomatic depression, and higher scores on a healthy dietary measure with decreased symptomatic depression [32]. A subsequent prospective study reported that diet quality was associated with adolescent mental health over a two-year period, even after taking mental health at baseline into account [33]. Moreover, improvements in diet quality were mirrored by improvements in mental health, while reductions in diet quality were associated with declining psychological functioning over the follow-up period. More recently still, a cross-sectional study of German children participating in both the GINIplus and LISAplus cohort studies reported that higher diet quality was associated with fewer emotional symptoms, while increased confectionary consumption had a positive relationship with emotional symptomatology [34].

\section{How strong is the evidence for a causal effect of diet on common mental disorders?}

Although the existing observational data are consistent, it is still an unresolved question as to whether the observed associations are a result of causal relationships between diet and mental health, or whether the associations between diet and common mental disorders are due to 
residual confounding by socioeconomic status or healthy lifestyle behaviors in general, or confounding by unrecognized third factors. Further, reverse causality is not entirely ruled out. The same methodological challenges apply to studies of an eventual effect of physical activity and smoking on mental health. The picture is further complicated by the recognition of the bidirectional relationship between diet and mental health, wherein appetite changes may be a result of mental health symptoms rather than a causative factor. Although the large majority of the previous observational studies have addressed confounding, and the prospective studies have assessed the reverse causality hypothesis, there are obvious limitations to observational studies as regards determining causality. Moreover, apart from one report of no relationship between measures of healthy diet and depression in male, but not female, college students [35] and another study of 865 women reporting no relationship between dietary patterns and postpartum depression [36], there is a dearth of negative studies. There are no published papers examining the issue of publication bias in the diet-common mental disorders literature, thus we cannot exclude publication bias in favor of positive findings.

On the other hand, it appears that the published studies on the diet-mental health association do satisfy most of the Bradford Hill criteria for causality [37]: that of consistency, with concordant findings and effect sizes across cultures, genders and age groups, with multiple methods used to assess diet quality and mental health; biological gradient $[15,18,19,21,24,32,33]$; temporality [18-21,33]; biological plausibility $[38,39]$; and coherence of the findings with what we already know about the impact of habitual diet on noncommunicable illnesses. However, we only have very preliminary experimental evidence at this time [40].

In contrast to physical activity-depression research, randomized controlled trial evidence for the diet-common mental disorders association is lacking. However, such trials, when conducted, will present myriad methodological problems, as often seen in the field of depression research, such as difficulties with blinding and the problems inherent in conducting randomized controlled trials in patients with depression [41]. Beyond such trials in clinical samples, proving the effectiveness of universal prevention is also problematic, given the substantial statistical power required [42]. However, the reduction in smoking in the general population in many western societies is clearly the result of primary prevention at a population level [43], despite the lack of evidence from randomized controlled trials. Consequently, we would argue that primary prevention holds considerable promise for reducing the burden of depression and anxiety in the population, in concert with selected and indicated prevention, as well as treatment.

\section{Mechanisms}

Diet, exercise and smoking may influence mental health through a number of different pathways, including via modification of neurotrophins critical to depression $[44,45]$. Diet, smoking and exercise also influence systemic inflammation [46,47], which is thought to play a role in the genesis of depression [48]. Inflammation is a common pathophysiological mechanism thought to, at least in part, underpin the bidirectional relationships between depression and noncommunicable illnesses such as obesity [49], cardiovascular disease and type 2 diabetes [50]. This suggests immune dysregulation as a key shared pathophysiological pathway by which poor lifestyle practices contribute to both the common mental disorders and the noncommunicable disorders [51].

\section{Prevention: taking a population health approach to the common mental disorders}

The 2010 World Health Organization Global Status Report highlights the impact of the changing environmental determinants of the noncommunicable disorders, including poor dietary and physical activity behaviors that have been driven by changes to the global food supply systems, policy, and marketing, as well as increasing urbanization [52]. It outlines and promotes population-wide preventive interventions targeting lifestyle behaviors, primarily aimed at reducing cardiovascular diseases, cancers, diabetes and chronic lung diseases. Although mental health disorders are mentioned as part of the 'broader scope of the noncommunicable conditions,' the prevention of mental health problems using these targeted lifestyle strategies is not specifically addressed. However, we believe that it is both feasible and timely to use our emerging understanding of the impact on mental health of lifestyle behaviors to begin to develop effective, sustainable, population-level prevention initiatives for the common mental disorders. The challenge is how to expand from the nascent epidemiological evidence to develop and evaluate a prevention system for lifestyle-related mental ill health.

\section{A strategy for moving forward}

There is agreement that decreasing lifestyle-related risk must address a complex and interconnected mix of etiological factors, from individual behaviors to cultural norms and policy environments [53]. To begin to develop universal prevention approaches for the common mental disorders, it is necessary to link policy options with epidemiology and biological sciences. As such, we would argue that there is a continuing need to generate quality epidemiological evidence to address the identified shortcomings in the literature outlined above. Further research that attempts to disentangle the multitudinous interacting social, medical, behavioral, cultural and biological factors 
that impact upon both diet quality and mental illness risk is required, while systematic reviews of the diet-mental health observational research, with best evidence syntheses, would also be a valuable and timely contribution to this developing field.

Epidemiological studies should also gather biomarker data that elucidate the role of biological factors, such as oxidative stress, inflammation and neurotrophic mechanisms, as mediators in the relationship between lifestyle factors and the high prevalence mental illnesses. While there are data to show that diet quality, physical activity and mental health are each independently associated with neurotrophin levels and inflammatory and oxidative processes, to date there have been few studies directly addressing mediation via biological mechanisms. Such studies are necessary to either support or refute the case for causal biological relationships and to attempt to explicate the fundamental processes by which lifestyle may influence common mental disorders. There is also a pressing need for evidence from methodologically rigorous randomized controlled trials of dietary improvement as a treatment intervention in those with existing depressive illness. Although not addressing the question of prevention, such evidence - if positive - would be further support for direct causal relationships.

The next strategy advocated is to leverage on existing intervention studies in the field of obesity prevention research to assess the impact of lifestyle improvement on mental health outcomes, particularly in young people. The majority of mental health problems have their onset in childhood and adolescence [54] and this is where the potential for prevention is likely to be greatest. The recent Cochrane Review of effective strategies to prevent obesity in children found strong evidence to support beneficial effects of child obesity prevention programs on weight gain, particularly for programs targeted to children aged six to twelve years [55]. Given that the strategies employed to reduce the prevalence of obesity in children and adolescents overlap substantially with the objective of reducing the prevalence of mental health problems in children and adolescents through lifestyle improvement, the potential to leverage on existing and planned studies in this field and apply the findings to mental health prevention is clear. In this way, mental health research can avoid the failures of previous approaches to obesity prevention and build on the successes. In parallel, economic evaluations of such interventions are necessary to afford comparisons of various prevention models and the projection of the impact and cost-effectiveness of different policy and environmental changes at a population level.

Previous analyses of the costs and benefits of various approaches to public health, including the Assessing CostEffectiveness Prevention study [56], have identified that policy approaches to prevention are more cost-effective than health promotion or clinical interventions. As public health policy is the key responsibility of government, government must be at the forefront of prevention initiatives. Suggested priority actions overlap with those for noncommunicable diseases and include policies to improve the food and built environments and greater funding for prevention programs, keeping always in mind the impact on social equity [53].

It is also necessary to incorporate these proposed prevention strategies with attempts to address other risk factors. Childhood abuse and neglect are critical risks, however they are arguably better addressed via the justice and social welfare systems, where active programs are in play. Similarly, the issue of how society should address the regulatory and therapeutic framework of drug and alcohol abuse is of core salience to risk and prevention. Western societies are increasingly nuclear, fragmented, mobile and anomic. The lack of social connectedness is a risk for depression, and similarly merits attention. Thus, policy efforts aimed at prevention, as well as public health messages and educational programs developed in partnership with public health and advocacy groups, will need to integrate these new data regarding lifestyle with those previously understood. From a clinical perspective, support for lifestyle improvement should be routinely provided to all patients with depression and incorporated into treatment guidelines [57].

\section{What sort of impact can we expect to have?}

It is important to acknowledge the likely limitations of lifestyle modification in the prevention of the common mental disorders in individuals. In the observational studies, diet and physical activity do not account for a large proportion of the variance in psychological symptomatology. However, there are no identified factors, other than genetics, that account for any more than a small percentage of the variance in depression. Given the size of the burden of illness, the benefits of even a minimal impact on the prevalence of depression will be substantial, as even modest benefits at the individual level accrue to the entire population. Finally, it should be acknowledged that the evidence base for lifestyle as a true causal risk factor for common mental disorders is still developing. However, the benefits to physical health of improvements in lifestyle behaviors are well-established and the precautionary principle provides justification for beginning the development of the outlined programs in the absence of unequivocal evidence.

\section{Summary}

The identification of 'modifiable social and biological risk factors across the life course' and the need to 'advance prevention and implementation of early interventions' were recently nominated as the first two grand challenges in global mental health [58]. We hereby present the case 
for inclusion of the common mental disorders under the noncommunicable diseases umbrella, based on the recent identification of lifestyle as a modifiable risk factor, and call for the development of a coordinated strategy for the universal primary prevention of the common mental disorders that builds on the established and developing approaches to the noncommunicable somatic diseases.

\section{Acknowledgements}

FNJ has received Grant/Research support from the Brain and Behaviour Research Institute (NARSAD), the National Health and Medical Research Council (NHMRC), Australian Rotary Health, the Geelong Medical Research Foundation, the lan Potter Foundation, Eli Lilly and The University of Melbourne and has been a paid speaker for Sanofi-Synthelabo, Janssen Cilag, Servier, Pfizer, Astra Zeneca, Network Nutrition, Generation Next/Health Ed and Eli Lilly. She is supported by an NHMRC Postdoctoral Training Fellowship (\#628912). AM received funding from the Norwegian Research Council for this work. MB has received Grant/Research Support from the National Institutes for Health, Cooperative Research Centre, Simons Autism Foundation, Cancer Council of Victoria, Stanley Medical Research Foundation, MBF, the National Health and Medical Research Council, Beyond Blue, Geelong Medical Research Foundation, Bristol Myers Squibb, Eli Lilly, Glaxo SmithKline, Organon, Novartis, Mayne Pharma and Servier, has been a speaker for Astra Zeneca, Bristol Myers Squibb, Eli Lilly, Glaxo SmithKline, Janssen Cilag, Lundbeck, Merck, Pfizer, Sanofi-Synthelabo, Servier, Solvay and Wyeth, and served as a consultant to Astra Zeneca, Bristol Myers Squibb, Eli Lilly, Glaxo SmithKline, Janssen Cilag, Lundbeck and Servier. These funding bodies did not play a role in the design or content of this work. The authors wish to thank Dr Sharon Brennan and Ms Shae Quirk for undertaking a systematic review of the diet quality and mental health relationship, some of the results of which informed the narrative review in this commentary.

\section{Author details}

'Deakin University, School of Medicine and Barwon Health, PO Box 281, Geelong, 3220, Australia. ${ }^{2}$ The University of Melbourne, Department of Psychiatry, Parkville, 3010, Australia. ${ }^{3}$ Norwegian Institute of Public Health, Division of Mental Health, Kalfarveien 31, 5018, Bergen, Norway. ${ }^{4}$ University of New South Wales, School of Psychiatry, Black Dog Institute, Building Hospital Road, Prince of Wales Hospital, Randwick, 2031, Australia. ${ }^{5}$ The Florey Institute of Neuroscience and Mental Health, Genetics Lane, Royal Parade, The University of Melbourne, Parkville, 3010, Australia. ${ }^{6}$ Orygen Youth Health Research Centre, 35 Poplar Road, Parkville, 3052, Australia.

\section{Authors' contributions}

FNJ led the development and authorship of this article. AM and MB contributed equally to intellectual content and manuscript preparation. All authors have read and approved the article for publication.

\section{Authors' information}

FNJ is a psychiatric epidemiologist and Principal Research Fellow within the School of Medicine at Deakin University, Geelong, Australia. She is also an Honorary Research fellow in the Department of Psychiatry at the University of Melbourne, Australia. AM is a psychiatric epidemiologist and Professor at the Norwegian Institute of Public Health, with academic affiliations with the University of Bergen, Norway and the University of New South Wales, School of Psychiatry, Sydney, Australia. MB is Alfred Deakin Professor of Psychiatry and the Director of the Strategic Research Centre for Psychiatry and Epidemiology within the School of Medicine, Deakin University; Professorial Research Fellow at The Florey Institute of Neuroscience and Mental Health and the Department of Psychiatry at the University of Melbourne; and leads the first episode bipolar program at Orygen Youth Health, Melbourne, Australia.

\section{Competing interests}

The authors declare that they have no competing interests.

Received: 20 June 2012 Accepted: 27 November 2012 Published: 27 November 2012

\section{References}

1. Mykletun A, Overland S, Dahl AA, Krokstad S, Bjerkeset O, Glozier N, Aaro LE, Prince M: A population-based cohort study of the effect of common mental disorders on disability pension awards. Am J Psychiatry 2006, 163:1412-1418.

2. Mykletun A, Bjerkeset O, Overland S, Prince M, Dewey M, Stewart R: Levels of anxiety and depression as predictors of mortality: the HUNT study. $\mathrm{Br}$ J Psychiatry 2009, 195:1 18-125.

3. Cuijpers P, Beekman AT, Reynolds CF: Preventing depression: a global priority. JAMA 2012, 307:1033-1034.

4. Lucas M, Mekary R, Pan A, Mirzaei F, O'Reilly EJ, Willett WC, Koenen K, Okereke Ol, Ascherio A: Relation between clinical depression risk and physical activity and time spent watching television in older women: a 10-year prospective follow-up study. Am J Epidemiol 2011, 174:1017-1027.

5. Harvey SB, Hotopf M, Overland S, Mykletun A: Physical activity and common mental disorders. Br J Psychiatry 2010, 197:357-364.

6. Pasco JA, Williams LJ, Jacka FN, Henry MJ, Coulson CE, Brennan SL, Leslie E, Nicholson GC, Kotowicz MA, Berk M: Habitual physical activity and the risk for depressive and anxiety disorders among older men and women. Int Psychogeriatr 2011, 23:292-298.

7. Stathopoulous G, Powers MB, Berry AC, Smits JAJ, Otto M: Exercise interventions for mental health: a quantitative and qualitative review. Clin Psychol Sci Prac 2006, 13:179-193.

8. Mykletun A, Overland S, Aaro LE, Liabo HM, Stewart R: Smoking in relation to anxiety and depression: evidence from a large population survey: the HUNT study. Eur Psychiatry 2008, 23:77-84

9. Pasco JA, Williams L, Jacka FN, Ng F, Henry MJ, Nicholson GC, Kotowicz MA, Berk M: Tobacco smoking as a risk factor for major depressive disorder: population-based study. Br J Psychiatry 2008, 193:322-326.

10. Breslau N, Novak SP, Kessler RC: Daily smoking and the subsequent onset of psychiatric disorders. Psychol Med 2004, 34:323-333.

11. Appleton KM, Rogers PJ, Ness AR: Updated systematic review and metaanalysis of the effects of $n-3$ long-chain polyunsaturated fatty acids on depressed mood. Am J Clin Nutr 2010, 91:757-770.

12. Taylor MJ, Carney SM, Goodwin GM, Geddes JR: Folate for depressive disorders: systematic review and meta-analysis of randomized controlled trials. J Psychopharmacol 2004, 18:251-256

13. Jorm AF, Christensen H, Griffiths KM, Rodgers B: Effectiveness of complementary and self-help treatments for depression. Med J Aust 2002, , 176 Suppl: S84-96.

14. Murakami K, Sasaki S: Dietary intake and depressive symptoms: a systematic review of observational studies. Mol Nutr Food Res 2010, 54:471-488.

15. Jacka FN, Pasco JA, Mykletun A, Williams LJ, Hodge AM, O'Reilly SL, Nicholson GC, Kotowicz MA, Berk M: Association between western and traditional diets and depression and anxiety in women. Am J Psychiatry 2010, 167:305-311.

16. Jacka FN, Pasco JA, Mykletun A, Williams LJ, Nicholson GC, Kotowicz MA Berk M: Diet quality in bipolar disorder in a population-based sample of women. J Affect Disord 2011, 129:332-337.

17. Jacka FN, Mykletun A, Berk M, Bjelland I, Tell GS: The association between habitual diet quality and the common mental disorders in communitydwelling adults: the Hordaland Health study. Psychosom Med 2011, 73:483-490.

18. Sanchez-Villegas A, Delgado-Rodriguez M, Alonso A, Schlatter J, Lahortiga F, Majem LS, Martinez-Gonzalez MA: Association of the Mediterranean dietary pattern with the incidence of depression: the Seguimiento Universidad de Navarra/University of Navarra follow-up (SUN) cohort. Arch Gen Psychiatry 2009, 66:1090-1098.

19. Sanchez-Villegas A, Toledo E, de Irala J, Ruiz-Canela M, Pla-Vidal J, MartinezGonzalez MA: Fast-food and commercial baked goods consumption and the risk of depression. Public Health Nutr 2012, 15:424-432.

20. Akbaraly TN, Brunner EJ, Ferrie JE, Marmot MG, Kivimaki M, SinghManoux A: Dietary pattern and depressive symptoms in middle age. $\mathrm{Br} J$ Psychiatry 2009, 195:408-413.

21. Chatzi L, Melaki V, Sarri K, Apostolaki I, Roumeliotaki T, Georgiou V, Vassilaki M, Koutis A, Bitsios P, Kogevinas M: Dietary patterns during pregnancy and the risk of postpartum depression: the mother-child 'Rhea' cohort in Crete, Greece. Public Health Nutr 2011, 14:1663-1670. 
22. Nanri A, Kimura Y, Matsushita Y, Ohta M, Sato M, Mishima N, Sasaki S, Mizoue T: Dietary patterns and depressive symptoms among Japanese men and women. Eur J Clin Nutr 2010, 64:832-839.

23. Aihara $Y$, Minai J, Aoyama A, Shimanouchi S: Depressive symptoms and past lifestyle among Japanese elderly people. Community Ment Health J 2011, 47:186-193.

24. Liu C, Xie B, Chou CP, Koprowski C, Zhou D, Palmer P, Sun P, Guo Q, Duan L, Sun $X$, Anderson Johnson C: Perceived stress, depression and food consumption frequency in the college students of China Seven Cities. Physiol Behav 2007, 92:748-754.

25. Kuczmarski MF, Cremer Sees A, Hotchkiss L, Cotugna N, Evans MK, Zonderman AB: Higher Healthy Eating Index-2005 scores associated with reduced symptoms of depression in an urban population: findings from the Healthy Aging in Neighborhoods of Diversity Across the Life Span (HANDLS) study. J Am Diet Assoc 2010, 110:383-389.

26. Beydoun MA, Fanelli Kuczmarski MT, Beydoun HA, Shroff MR, Mason MA, Evans MK, Zonderman AB: The sex-specific role of plasma folate in mediating the association of dietary quality with depressive symptoms. J Nutr 2010, 140:338-347.

27. Crawford GB, Khedkar A, Flaws JA, Sorkin JD, Gallicchio L: Depressive symptoms and self-reported fast-food intake in midlife women. Prev Med 2011, 52:254-257.

28. Pagoto SL, Ma Y, Bodenlos JS, Olendzki B, Rosal MC, Tellez T, Merriam P, Ockene IS: Association of depressive symptoms and lifestyle behaviors among Latinos at risk of type 2 diabetes. J Am Diet Assoc 2009, 109:1246-1250.

29. Nanri A, Hayabuchi H, Ohta M, Sato M, Mishima N, Mizoue T: Serum folate and depressive symptoms among Japanese men and women: a crosssectional and prospective study. Psychiatry Res 2012.

30. Oddy WH, Robinson M, Ambrosini GL, O'Sullivan TA, de Klerk NH, Beilin LJ Silburn SR, Zubrick SR, Stanley FJ: The association between dietary patterns and mental health in early adolescence. Prev Med 2009, 49:39-44.

31. Weng TT, Hao JH, Qian QW, Cao H, Fu JL, Sun Y, Huang L, Tao FB: Is there any relationship between dietary patterns and depression and anxiety in Chinese adolescents? Public Health Nutr 2012, 15:673-382.

32. Jacka FN, Kremer PJ, Leslie E, Berk M, Patton G, Toumbourou JW, Williams JW: Associations between diet quality and depressed mood in adolescents: results from the Healthy Neighbourhoods study. Aust N Z J Psychiatry 2010, 44:435-442

33. Jacka F, Kremer PJ, Berk M, de Silva-Sanigorski A, Moodie M, Leslie E, Pasco J, Swinburn B: A prospective study of diet quality and mental health in adolescents. PLoS One 2011, 6:e24805.

34. Kohlboeck G, Sausenthaler S, Standl M, Koletzko S, Bauer CP, von Berg A, Berdel D, Kramer U, Schaaf B, Lehmann I, Herbarth O, Heinrich J: Food intake, diet quality and behavioral problems in children: results from the GINI-plus/LISA-plus Studies. Ann Nutr Metab 2012, 60:247-256.

35. Mikolajczyk RT, El Ansari W, Maxwell AE: Food consumption frequency and perceived stress and depressive symptoms among students in three European countries. Nutr J 2009, 8:31

36. Okubo H, Miyake Y, Sasaki S, Tanaka K, Murakami K, Hirota Y: Dietary patterns during pregnancy and the risk of postpartum depression in Japan: the Osaka Maternal and Child Health Study. Br J Nutr 2011, 105:1251-1257.

37. Bradford Hill A: The environment and disease: association or causation? Proc R Soc Med 1965, 58(5):295-300.

38. Jacka FN, Berk M: Food for thought. Acta Neuropsychiatrica 2007, 19:321-323.

39. Milaneschi $Y$, Bandinelli S, Penninx BW, Vogelzangs N, Corsi AM, Lauretani $F$, Kisialiou A, Vazzana R, Terracciano A, Guralnik JM, Ferrucci L: Depressive symptoms and inflammation increase in a prospective study of older adults: a protective effect of a healthy (Mediterranean-style) diet. $\mathrm{Mo}$ Psychiatry 2011, 16:589-590

40. Imayama I, Alfano CM, Kong A, Foster-Schubert KE, Bain CE, Xiao L, Duggan C, Wang CY, Campbell KL, Blackburn GL, McTiernan A: Dietary weight loss and exercise interventions effects on quality of life in overweight/obese postmenopausal women: a randomized controlled trial. Int J Behav Nutr Phys Act 2011, 8:118.

41. Schulberg HC, Coulehan JL, Block MR, Lave J, Rodriguez E, Scott CP, Madonia MJ, Imber S, Perel J: Clinical trials of primary care treatments for major depression: issues in design, recruitment and treatment. Int $J$ Psychiatry Med 1993, 23:29-42.

42. Cuijpers P: Examining the effects of prevention programs on the incidence of new cases of mental disorders: the lack of statistical power. Am J Psychiatry 2003, 160:1385-1391.

43. Jha P, Chaloupka FJ, Corrao M, Jacob B: Reducing the burden of smoking world-wide: effectiveness of interventions and their coverage. Drug Alcohol Rev 2006, 25:597-609.

44. Sharma S, Zhuang Y, Gomez-Pinilla F: High-fat diet transition reduces brain DHA levels associated with altered brain plasticity and behaviour. Sci Rep 2012, 2:431

45. Moylan S, Maes M, Wray NR, Berk M: The neuroprogressive nature of major depressive disorder: pathways to disease evolution and resistance, and therapeutic implications. Mol Psychiatry 2012.

46. Lopez-Garcia E, Schulze MB, Fung TT, Meigs JB, Rifai N, Manson JE, Hu FB: Major dietary patterns are related to plasma concentrations of markers of inflammation and endothelial dysfunction. Am J Clin Nutr 2004, 80:1029-1035.

47. Duivis HE, de Jonge P, Penninx BW, Na BY, Cohen BE, Whooley MA: Depressive symptoms, health behaviors, and subsequent inflammation in patients with coronary heart disease: prospective findings from the heart and soul study. Am J Psychiatry 2011, 168:913-920.

48. Pasco JA, Nicholson GC, Williams LJ, Jacka FN, Henry MJ, Kotowicz MA Schneider $\mathrm{HG}$, Leonard BE, Berk M: Association of high-sensitivity Creactive protein with de novo major depression. Br J Psychiatry 2010, 197:372-377

49. Soczynska JK, Kennedy SH, Woldeyohannes HO, Liauw SS, Alsuwaidan M, Yim CY, Mclntyre RS: Mood disorders and obesity: understanding inflammation as a pathophysiological nexus. Neuromolecular Med 2011, 13:93-116

50. Renn BN, Feliciano L, Segal DL: The bidirectional relationship of depression and diabetes: a systematic review. Clin Psychol Rev 2011, 31:1239-1246.

51. Maes M: Depression is an inflammatory disease, but cell-mediated immune activation is the key component of depression. Prog Neuropsychopharmacol Biol Psychiatry 2011, 35:664-675.

52. World Health Organization (WHO): Global status report on noncommunicable diseases 2010. 2011, Geneva: WHO.

53. Gortmaker SL, Swinburn BA, Levy D, Carter R, Mabry PL, Finegood DT, Huang T, Marsh T, Moodie ML: Changing the future of obesity: science, policy, and action. Lancet 2011, 378:838-847.

54. Merikangas KR, He JP, Burstein M, Swanson SA, Avenevoli S, Cui L, Benjet C, Georgiades K, Swendsen J: Lifetime prevalence of mental disorders in U.S. adolescents: results from the National Comorbidity Survey ReplicationAdolescent Supplement (NCS-A). J Am Acad Child Adolesc Psychiatry 2010, 49:980-989.

55. Waters E, de Silva-Sanigorski A, Hall BJ, Brown T, Campbell KJ, Gao Y, Armstrong R, Prosser L, Summerbell CD: Interventions for preventing obesity in children. Cochrane Database Syst Rev 2011, 12:CD001871.

56. Vos T, Carter R, Barendregt J, Mihalopoulos C, Veerman L, Magnus A, Cobiac L, Bertram M, Wallace A, Team AP: Assessing Cost-Effectiveness in Prevention (ACE-Prevention): final report. Melbourne: University of Queensland, Brisbane and Deakin University; 2010.

57. Jacka F, Berk M: Depression, diet and exercise. MJA Open 2012, Suppl 4: 21-23.

58. Collins PY, Patel V, Joestl SS, March D, Insel TR, Daar AS, Anderson W, Dhansay MA, Phillips A, Shurin S, Walport M, Ewart W, Savill SJ, Bordin IA, Costello EJ, Durkin M, Fairburn C, Glass RI, Hall W, Huang Y, Hyman SE, Jamison K, Kaaya S, Kapur S, Kleinman A, Ogunniyi A, Otero-Ojeda A, Poo MM, Ravindranath V, Sahakian BJ, et al: Grand challenges in global mental health. Nature 2011, 475:27-30.

\section{Pre-publication history}

The pre-publication history for this paper can be accessed here: http://www.biomedcentral.com/1741-7015/10/149/prepub

doi:10.1186/1741-7015-10-149

Cite this article as: Jacka et al:: Moving towards a population health approach to the primary prevention of common mental disorders. BMC Medicine 2012 10:149 